\title{
Risk factors associated with ticks and Rickettsia spp. exposure in wild boars (Sus scrofa), hunting dogs, and hunters of Brazil
}

\author{
Louise Bach Kmetiuk ${ }^{1}$ (D) Thiago Fernandes Martins² (i), Renato van Wilpe Bach ${ }^{3}$, Camila Marinelli Martins ${ }^{3}$ (i), \\ Ivan Roque de Barros-Filho ${ }^{4}$, Leandro Cavalcante Lipinski ${ }^{3}$, Giovani Marino Fávero ${ }^{5}$, Andrea Pires dos Santos ${ }^{6}$ (D) \\ and Alexander Welker Biondo ${ }^{1,4}$ (i)
}

1. Graduate College of Cellular and Molecular Biology, Federal University of Paraná (UFPR), Coronel Francisco Heráclito dos Santos Avenue, 100, Curitiba, Paraná State, 81531-970, Brazil; 2. Department of Preventive Veterinary Medicine and Animal Health, School of Veterinary Medicine and Animal Science, University of São Paulo, Orlando de Paiva Street, 87, São Paulo, SP, 05508 270, Brazil; 3. Department of Medicine, State University of Ponta Grossa, Carlos Cavalcante Avenue, 4748, Ponta Grossa, PR, 84030-900, Brazil; 4. Department of Veterinary Medicine, Federal University of Paraná State, Funcionários Street, 1540, Curitiba, Paraná State, 80035-050, Brazil; 5. Department of General Biology,

State University of Ponta Grossa, General Carlos Cavalcanti, 4748, Ponta Grossa, Paraná State, 84030-900, Brazil;

6. Department of Comparative Pathobiology, School of Veterinary Medicine, Purdue University, Harrison Street, 725, West Lafayette, Indiana, 47907-2027, USA.

Corresponding author: Alexander Welker Biondo, e-mail: abiondo@ufpr.br

Co-authors: LBK: louisebachk@gmail.com,TFM: thiagodogo@hotmail.com, RVWB: renatovwbach@gmail.com, CMM: cami.marinelli@gmail.com, IRB: ivanbarf@ufpr.br, LCL: leandrolipinski@yahoo.com.br, GMF: gmfavero@uepg.br, APS: santos1@purdue.edu

Received: 08-06-2021, Accepted: 30-08-2021, Published online: 25-10-2021

doi: www.doi.org/10.14202/vetworld.2021.2745-2749 How to cite this article: Kmetiuk LB, Martins TF, Bach RVW, Martins CM, de Barros-Filho IR, Lipinski LC, Fávero GM, dos Santos AP, Biondo AW (2021) Risk factors associated with ticks and Rickettsia spp. exposure in wild boars (Sus scrofa), hunting dogs, and hunters of Brazil, Veterinary World, 14(10): 2745-2749.

\begin{abstract}
Background and Aim: Wild boars have recently been implicated as the maintainers and carriers of Amblyomma spp. ticks, which are essential for Rickettsia spp. transmission. Consequently, wild boar hunting may increase the risk of tick exposure and subsequent human tick-borne infection and disease. Therefore, this study was conducted to evaluate the risk factors for ticks and Rickettsia spp. exposure in wild boars, hunting dogs, and hunters in Brazilian biomes.
\end{abstract}

Materials and Methods: The statistical relationship of Rickettsia spp. antibodies were evaluated using the Chi-square test in 80 wild boars, 170 hunting dogs, and 49 hunters.

Results: The only statistically significant difference in seropositivity found in this study was between male and female wild boars $(\mathrm{p}=0.034)$, probably associated with in-park exposure to Amblyomma brasiliense infected with Rickettsia spp.

Conclusion: The absence of statistical differences in the associated risk factors for hunting dogs and hunters may indicate a random exposure to Rickettsia spp.

Keywords: Brazilian spotted fever, hunting activities, wild boars.

\section{Introduction}

In recent years, wild boars have been implicated as the maintainers and carriers of Amblyomma spp. ticks in Brazil, which are essential for the transmission of Rickettsia spp., particularly Brazilian spotted fever (BSF) [1]. Wild boars are classified as exotic invasive species by Brazilian laws, and their hunting has been permitted nationwide, primarily using hunting dogs (Canis familiaris) for tracking and hunting [2,3].

Spotted fever has been considered as the most fatal tick-borne disease worldwide, and wild boars may spread infected ticks with Rickettsia spp. from their original habitats to other ecosystems, causing human exposure, particularly in specific human

Copyright: Kmetiuk, et al. Open Access. This article is distributed under the terms of the Creative Commons Attribution 4.0 International License (http://creativecommons.org/licenses/ by/4.0/), which permits unrestricted use, distribution, and reproduction in any medium, provided you give appropriate credit to the original author(s) and the source, provide a link to the Creative Commons license, and indicate if changes were made. The Creative Commons Public Domain Dedication waiver (http:// creativecommons.org/publicdomain/zero/1.0/) applies to the data made available in this article, unless otherwise stated. activities such as wild boar hunting [1]. Moreover, hunting dogs may elevate the risk of human infection when bringing infected Amblyomma spp. ticks back home [4].

Therefore, this study was conducted to evaluate the risk factors for exposure to ticks and Rickettsia spp. in wild boars, hunting dogs, and hunters in two different Brazilian biomes.

\section{Materials and Methods}

\section{Ethical approval}

This study was approved by the Ethics Committee of Animal Use (protocol number 059/2017) of the Federal University of Paraná, officially included as part of the annual activities of the City Secretary of Health at Ponta Grossa and approved by National Human Ethics Research Committee (number 97639017.7.0000.0102). In-park trapping and tick collection have been authorized by the Environment Institute of Paraná (authorization number 30/17) and by Chico Mendes Institute of Biology (authorization number 61805-2). 


\section{Study period and location}

The present study was conducted from November 2016 to May 2018. The risk of BSF was evaluated on preserved and degraded areas in the Atlantic Forest biome of South Brazil, including the Vila Velha State Park, and degraded areas in the Cerrado biome of Central-West Brazil, as reported previously [1].

\section{Sampling}

This investigation was a descriptive cross-sectional study of risk factors associated with Rickettsia spp. and parasitized ticks infesting wild boars, hunting dogs, and hunters [1].

Blood samples of wild boars, hunting dogs, and hunters were collected from October 2016 through May 2018. Blood samples from free-range wild boars in degraded areas were collected after killing them by a firearm according to Brazilian environmental laws. Furthermore, free-range wild boars from the State Park natural areas of Vila Velha were baited, trapped, and killed by a firearm. Blood samples from all wild boars were collected immediately after death by the intracardiac puncture. Blood samples from hunting dogs were collected by jugular puncture as approved by the Ethics Committee of Animal Use at the Federal University of Paraná (protocol 059/2017). Finally, the blood samples of hunters were collected by cephalic puncture as approved by the Ethical Appreciation at Ethics Committee in Human Health at the Brazilian Ministry of Health (protocol 97,639,017.7.0000.0102). All blood samples were collected in tubes without anticoagulants and maintained at room temperature $\left(25^{\circ} \mathrm{C}\right)$ until visible clot retraction, after which they were centrifuged at $1500 \mathrm{rpm}$ for $5 \mathrm{~min}$ and the resulting serum was stored at $-20^{\circ} \mathrm{C}$ until processing. In addition, ticks were collected from wild boars, hunting dogs, and hunters as approved by the Chico Mendes Institute of Biology.

Serum samples of wild boars, hunting dogs, and hunters were evaluated for the presence of Rickettsia amblyommatis strain Ac37, Rickettsia bellii strain CL, Rickettsia parkeri strain At24, Rickettsia rickettsii strain Taiaçu, and Rickettsia rhipicephali strain HJ5 by indirect immunofluorescent antibody assay, as described previously [1]. Sera samples were screened at a 1:64 dilution against each of the rickettsial antigens, and in a seropositive reaction, serial dilutions at 2 -fold increments were tested up to the endpoint titer. Ticks were randomly collected from wild boars, hunting dogs, and hunters, subjected to DNA extraction, and individually tested by standard polymerase chain reaction for tick mitochondrial $16 \mathrm{~S}$ rRNA and rickettsial gltA gene, as described earlier [1].

The statistical relationship of Rickettsia spp. antibodies were evaluated using the Chi-square test in 80 wild boars, 170 hunting dogs, and 49 hunters. For wild boars, the associations tested were between positivity and sex, age, body size, captured in anthropized and/ or natural area, and biome of capture; for hunting dogs, the evaluated associations were between positivity and sex, age, biome location, mobility, hunting frequency, hunting experience, and animal hygiene; and for hunters, the associations tested were between positivity and sex, age, household location, biome location, occupation, education, hunting method, hunting frequency, hunting experience, frequency of access to forest areas, observation of capybaras (Hydrochoerus hydrochaeris) and opossums (Didelphis spp.), number of hunters and family members at the household, hunting dog contact, own a hunter dog, ticks collected, previous tick contact, infestation, control and bites, and activities after hunting.

\section{Results}

A total of 80 wild boars, 170 hunting dogs, and 49 hunters were sampled. Serological analysis for Rickettsia spp. showed that $58 / 80(72.5 \%)$ wild boars, $24 / 170$ (14.1\%) hunting dogs, and 5/34 (14.7\%) hunters were seroreagent for Rickettsia spp., as previously reported [1].

Wild boar exposure to Rickettsia spp. was statistically significant in terms of sex, with females being more likely to be positive ( $\mathrm{p}=0.034)$; however, this was not associated with other risk factors, including age, area of capture, and between free-range and captured wild boars (Table-1). Hunting dog exposure to Rickettsia spp. antibodies showed no statistically significant differences, including sex, age, body score, hygiene, vaccination, limited dog mobility, hunting experience in years, and hunting frequency (Table-1).

Hunter exposure to Rickettsia spp. antibodies also demonstrated no statistically significant differences, including age, number of years living in rural areas, hunting experience in years, number of people and dogs in hunter household, occupation, income, education level, household location dog owner, peridomicile and dogs maintained indoors, contact with dogs of other hunters, presence of forest areas nearby the household, and presence of capybaras and opossums in hunting areas (Table-1).

The number of Amblyomma brasiliense, Amblyomma sculptum, Amblyomma dubitatum, and larvae of Amblyomma spp. ticks infesting wild boars showed no statistical differences for Rickettsia spp. seropositivity when compared between Atlantic Forest with Cerrado biomes and with degraded areas of Atlantic Forest.

Only Amblyomma aureolatum ticks were detected in hunting dogs from South Brazil [1], with no statistical significance associated with Rickettsia spp. seropositivity. Due to the asymmetric data distribution, the Shapiro-Wilk test $(p<0.000001)$ and the Mann-Whitney U non-parametric test were conducted to confirm the difference in Rickettsia spp. seropositivity $(20 \pm 14 ; 10,10-40)$ and seronegativity $(21 \pm 14$; $10,10-40)$ in groups of dogs with no statistically significant outcome (Table-1).

In the present study, 30/49 (61.2\%) sampled hunters reported previous tick contact and 23/49 (46.9\%) hunters reported tick bites. In addition, $11 / 30(36.6 \%)$ hunters reported exposure in all 
Table-1: Risk factors for seropositivity of anti-Rickettsia spp. antibodies in wild boars, hunting dogs, and hunters.

\begin{tabular}{|c|c|c|c|c|}
\hline \multirow[t]{2}{*}{ Risk factors of Rickettsia spp. } & \multirow{2}{*}{$\begin{array}{c}\text { Total } \\
\text { Yes/total (\%) }\end{array}$} & \multirow{2}{*}{$\frac{\text { Positive }}{\text { Yes/total (\%) }}$} & \multirow[t]{2}{*}{ OR (95\% CI) } & \multirow[t]{2}{*}{ p-value } \\
\hline & & & & \\
\hline \multicolumn{5}{|l|}{ Wild boar variables } \\
\hline \multicolumn{5}{|l|}{ Sex } \\
\hline Female & $51 / 80(63.7)$ & $41 / 51(80.4)$ & $2.89(1.05-7.96)$ & 0.034 \\
\hline Male & $29 / 80(36.2)$ & $17 / 29(58.6)$ & (ref) & \\
\hline$<6$ months & $18 / 80(22.5)$ & $13 / 18(72.2)$ & (ref) & \\
\hline \multicolumn{5}{|l|}{ Age } \\
\hline$<6$ months & $18 / 80(22.5)$ & $13 / 18(72.2)$ & (ref) & \\
\hline$>6$ months $-<1$ year old & $14 / 80(17.5)$ & $10 / 14(71.4)$ & $1.04(0.31-3.48)$ & 0.955 \\
\hline 1 year old & $48 / 80(60.0)$ & $35 / 48(72.9)$ & $1.08(0.29-4.04)$ & 0.913 \\
\hline \multicolumn{5}{|l|}{ Free range/captured } \\
\hline Free range & $14 / 80(17.5)$ & $11 / 14(78.6)$ & (ref) & \\
\hline Captured & $66 / 80(82.5)$ & $47 / 66(71.2)$ & $0.67(0.17-2.69)$ & 0.422 \\
\hline \multicolumn{5}{|l|}{ Capture area } \\
\hline Natural & $21 / 80(26.2)$ & $21 / 21(100)$ & (ref) & 0.390 \\
\hline Agricultural & $45 / 80(56.2)$ & $26 / 45(57.8)$ & $*$ & \\
\hline Anthropized & $14 / 80(17.5)$ & $11 / 14(78.6)$ & $*$ & \\
\hline Degraded Cerrado & $36 / 80(45.0)$ & $20 / 36(55.6)$ & $*$ & \\
\hline \multicolumn{5}{|l|}{ Biomes } \\
\hline Atlantic Forest & $21 / 80(26.2)$ & $21 / 21(100)$ & (ref) & 0.371 \\
\hline Degraded Atlantic Forest & $23 / 80(28.7)$ & $17 / 23(73.9)$ & $*$ & \\
\hline \multicolumn{5}{|l|}{ Tick collection } \\
\hline Yes & $31 / 80(38.7)$ & $26 / 31(83.9)$ & $2.76(0.89-8.49)$ & 0.070 \\
\hline No & $49 / 80(61.2)$ & $32 / 49(65.3)$ & (ref) & \\
\hline \multicolumn{5}{|l|}{ Dog variables } \\
\hline \multicolumn{5}{|l|}{ Age } \\
\hline$<1$ year old & $27 / 170(15.8)$ & $3 / 27(11.1)$ & (ref) & \\
\hline$>1-<8$ years old & $113 / 170(66.5)$ & $15 / 113(13.3)$ & $2.00(0.45-8.94)$ & 0.364 \\
\hline$>8$ years old & $30 / 170(17.6)$ & $6 / 30(20.0)$ & $1.63(0.57-4.65)$ & 0.358 \\
\hline Body size & & & & \\
\hline Small & $5 / 170(2.9)$ & $2 / 5(40.0)$ & (ref) & \\
\hline Medium & $151 / 170(88.8)$ & $20 / 151(13.2)$ & $0.25(0.02-2.58)$ & 0.244 \\
\hline Large & $14 / 170(8.2)$ & $2 / 14(14.3)$ & $1.09(0.23-5.24)$ & 0.913 \\
\hline Hygiene & & & & \\
\hline Yes & $86 / 170(50.6)$ & $9 / 86(10.5)$ & $0.54(0.22-1.31)$ & 0.166 \\
\hline No & $84 / 170(49.4)$ & $15 / 84(17.9)$ & (ref) & \\
\hline Vaccination & & & & \\
\hline Yes & $169 / 170(99.4)$ & $24 / 169(14.2)$ & & 0.859 \\
\hline No & $1 / 170(0.6)$ & 0 & (ref) & \\
\hline Deworming & & & & \\
\hline Yes & $170 / 170(100.0)$ & $24 / 170(14.1)$ & - & - \\
\hline No & 0 & & (ref) & \\
\hline Dog mobility & & & & \\
\hline Limited & $151 / 170(88.8)$ & $23 / 151(15.2)$ & (ref) & \\
\hline Unlimited & $19 / 170(11.2)$ & $1 / 19(5.3)$ & $0.31(0.04-2.43)$ & 0.212 \\
\hline Hunting experience & & & & \\
\hline$<1$ year & $43 / 170(25.3)$ & $7 / 43(16.3)$ & (ref) & \\
\hline$>1-<3$ years & $87 / 170(51.2)$ & $12 / 87(13.8)$ & $0.73(0.21-2.53)$ & 0.626 \\
\hline$>3$ years & $40 / 170(23.5)$ & $5 / 40(12.5)$ & $0.89(0.29-2.73)$ & 0.842 \\
\hline Hunting frequency (per month) & & & & \\
\hline Once & 29/170 (17.1) & $3 / 29(10.3)$ & (ref) & \\
\hline Twice & $63 / 170(37.1)$ & $8 / 63(12.7)$ & $2.48(0.34-17.83)$ & 0.368 \\
\hline 4 times & $69 / 170(40.6)$ & $11 / 69(15.9)$ & $1.96(0.35-11.16)$ & 0.446 \\
\hline 8 times & $9 / 170(5.3)$ & $2 / 9(22.2)$ & $1.51(0.28-8.23)$ & 0.636 \\
\hline Tick collection & & & & \\
\hline Yes & $7 / 170(4.1)$ & $1 / 7(14.3)$ & $1.01(0.12-8.82)$ & 0.663 \\
\hline No & $163 / 170(95.8)$ & $23 / 163(14.1)$ & (ref) & \\
\hline Biome & & & & \\
\hline Atlantic Forest & $147 / 170(86.5)$ & $21 / 147(14.3)$ & $1.11(0.30-4.07)$ & 0.586 \\
\hline Cerrado & $23 / 170(13.5)$ & $3 / 23(13.0)$ & (ref) & \\
\hline Hunter variables & & & & \\
\hline Sex & & & & \\
\hline Female & $7 / 49(14.3)$ & $0 / 7(0.0)$ & & 0.314 \\
\hline Male & $42 / 49(85.7)$ & $7 / 42(16.6)$ & (ref) & \\
\hline
\end{tabular}


Table-1: (Continued).

\begin{tabular}{|c|c|c|c|c|}
\hline \multirow[t]{2}{*}{ Risk factors of Rickettsia spp. } & \multirow{2}{*}{$\frac{\text { Total }}{\text { Yes/total }(\%)}$} & \multirow{2}{*}{$\frac{\text { Positive }}{\text { Yes/total (\%) }}$} & \multirow[t]{2}{*}{ OR (95\% CI) } & \multirow[t]{2}{*}{ p-value } \\
\hline & & & & \\
\hline \multicolumn{5}{|l|}{ Occupation } \\
\hline Retired and student & $8 / 49(16.3)$ & $0 / 8(0.0)$ & (ref) & \\
\hline Private work & $32 / 49(65.3)$ & $5 / 32(15.6)$ & & 0.644 \\
\hline Public work & $9 / 49(18.4)$ & $2 / 9(22.2)$ & & 0.118 \\
\hline \multicolumn{5}{|l|}{ Number of minimum wages } \\
\hline Up to three & $28 / 49(57.1)$ & $4 / 28(14.3)$ & (ref) & \\
\hline Four to eight & $16 / 49(32.6)$ & $2 / 16(12.5)$ & $0.7(0.1-7.6)$ & 0.744 \\
\hline Up to eight & $5 / 49(10.2)$ & $1 / 5(20.0)$ & $0.6(0.1-8.0)$ & 0.678 \\
\hline Basic education & $5 / 49(10.2)$ & $0 / 5(0.0)$ & & \\
\hline \multicolumn{5}{|l|}{ School level } \\
\hline High education & $12 / 49(24.5)$ & $2 / 12(16.7)$ & (ref) & 0.43 \\
\hline Graduate & 22/49 (44.9) & $2 / 22(9.1)$ & & 0.151 \\
\hline Postgraduate & $10 / 49(20.4)$ & $3 / 10(30.0)$ & & 0.220 \\
\hline \multicolumn{5}{|l|}{ Rural household location } \\
\hline Yes & $18 / 49(36.7)$ & $3 / 18(16.7)$ & $1.3(0.3-6.8)$ & 0.512 \\
\hline No & $31 / 49(63.3)$ & 4/31 (12.9) & (ref) & \\
\hline \multicolumn{5}{|l|}{ Registered hunter } \\
\hline Yes & $32 / 49(65.3)$ & $6 / 32(18.8)$ & $3.7(0.4-33.5)$ & 0.219 \\
\hline No & $17 / 49(34.7)$ & $1 / 17(5.9)$ & (ref) & \\
\hline \multicolumn{5}{|l|}{ Forest nearby the household } \\
\hline Yes & 23/49 (46.9) & 4/23 (17.4) & $1.6(0.3-8.1)$ & 0.429 \\
\hline No & $26 / 49(53.1)$ & $3 / 26(11.5)$ & (ref) & \\
\hline \multicolumn{5}{|l|}{ Dog owner } \\
\hline Yes & $5 / 49(10.2)$ & $5 / 38(13.2)$ & $0.7(0.1-4.1)$ & 0.500 \\
\hline No & $11 / 49(22.4)$ & $2 / 11(18.2)$ & (ref) & \\
\hline \multicolumn{5}{|l|}{ Dogs location } \\
\hline Without dogs & $12 / 49$ & $2 / 12(16.7)$ & (ref) & \\
\hline Peridomicile & $22 / 49$ & $3 / 22(13.6)$ & $0.8(0.1-5.5)$ & 0.812 \\
\hline Peridomicile and domiciled & $2 / 49$ & 2/14 (14.3) & $0.8(0.1-7.0)$ & 0.867 \\
\hline Domiciled & $1 / 49$ & $0 / 1$ & & \\
\hline \multicolumn{5}{|l|}{ Contact with dogs of other hunters } \\
\hline Yes & $39 / 49$ & 6/39 (15.4) & $1.6(0.2-15.4)$ & 0.996 \\
\hline No & $10 / 49(20.4)$ & 1/10 (10.0) & (ref) & 0.559 \\
\hline \multicolumn{5}{|c|}{ Presence of capybaras in hunting areas } \\
\hline Yes & 24/49 (49.0) & 4/24 (16.7) & $1.5(0.3-7.4)$ & 0.476 \\
\hline No & $25 / 49(51.0)$ & $3 / 25(12.0)$ & (ref) & \\
\hline \multicolumn{5}{|c|}{ Presence of opossum in hunting areas } \\
\hline Yes & $25 / 49(51.0)$ & 3/25 (12.0) & $0.7(0.1-3.4)$ & 0.641 \\
\hline No & 24/49 (49.0) & 4/24 (16.7) & (ref) & \\
\hline
\end{tabular}

seasons, 13/30 (43.3\%) hunters reported exposure during summer, $1 / 30(3.3 \%)$ hunter reported exposure during spring, and 1/30 (3.3\%) hunter reported exposure during autumn and winter. A tick check inspection after hunting was reported by $30 / 49(59.2 \%)$ hunters, and the use of a repellent was reported by only $1 / 49(0.2 \%)$ hunter. After hunting, $14 / 49(28.6 \%)$ hunters mentioned taking a shower, and 35/49 (71.4\%) hunters reported slaughtering wild boars (Table-1).

\section{Discussion}

In this study, no associated risk factor was statistically significant for wild boars, hunting dogs, or hunters with seropositivity to Rickettsia spp., except for wild boar sex, with females being more likely positive $(p=0.034)$. This finding may be due to the high exposure of in-park wild boars, mostly females, because previous research has shown a "forest border effect" risk for dogs and human beings [5].

Hence, the statistically significant differences in seropositivity between $17 / 29(58.6 \%)$ wild boar males and 41/51 (80.4\%) females could be related to the most prevalent wild boar sex and tick species sampled in the natural areas. Not surprisingly, 14/21 (66.6\%) wild boar females were slaughtered in-park, all of which were seropositive to Rickettsia spp. and had A. brasiliense ticks [1].

Although Brazilian hunters may equally hunt male and female wild boars, hunting has been prohibited in state parks, which may serve as a nursery to females [3]. Moreover, male wild boars have demonstrated a higher variation of roaming distance [6], indicating that they are more likely to cross park limits toward surrounding agricultural areas.

The frequency of dog contact with forests has been associated with the occurrence of Rickettsia spp. and Amblyomma spp. transmission [7]. In the present study, the absence of statistical differences in sex, age, body size, hygiene, vaccination, mobility, hunting experience, and frequency, tick collection, the group size of dogs, and biomes may indicate that hunting dogs are exposed to Rickettsia spp., irrespective of the associated risk factors. 
Although no study has focused on hunter exposure, people infected with BSF were found to be primarily white males aged between 20 and 64 years from the rural areas of South and Southeast Brazil, visiting natural environments (66.7\%), exposed to ticks (72.7\%), and contacting capybaras (15.6\%), dogs and cats $(42.4 \%)$, cattle $(17.2 \%)$, and horses $(17.4 \%)$ [8]. Therefore, the absence of statistical differences in the present study may indicate that hunters are exposed to Rickettsia spp., irrespective of their sex, age, occupation, income, education, household location, owning a dog, contact with hunting dogs, presence of capybaras or opossums, number of years lived in rural areas, hunting experience, and number of people and dogs in the hunter's household.

Finally, all ticks collected in these areas were negative for the presence of Rickettsia spp. as they have rarely infected BSF-non-endemic areas [1]. In Southeast Brazil, high capybara population has been associated with a high tick infestation rate in BSFendemic areas [9], with wild boar occurrence reportedly overlapping such areas [10].

\section{Conclusion}

The entry of wild boars, hunting dogs, and hunters into tick habitats may lead to bites and consequent infection with Rickettsia spp. The only statistically significant association with seropositivity found in this study was the increased risk due to hunting female wild boars, which is probably associated with in-park exposure to A. brasiliense and Rickettsia spp. Furthermore, the absence of statistical differences in the associated risk factors for hunting dogs and hunters may indicate a random exposure to Rickettsia spp.

\section{Authors' Contributions}

LBK, APS, and AWB: Conceptualization. LBK, TFM, RVWB, CMM, IRB, LCL, GMF, APS, and AWB: Data collection and data analysis. LBK and AWB: Drafted and revised the manuscript. All authors read and approved the final manuscript.

\section{Acknowledgments}

The authors also thank the Public Health Department of Ponta Grossa for the human blood samplings and David George Elliff for editing and improving the article. This study was funded by the Araucária Foundation for Scientific and Technological Development of Paraná State, Brazil (SUS2020111000007).

\section{Competing Interests} interests.

The authors declare that they have no competing

\section{Publisher's Note}

Veterinary World remains neutral with regard to jurisdictional claims in published institutional affiliation.

\section{References}

1. Kmetiuk, L.B., Krawczak, F.S., Machado, F.P., Paploski, F.A.D., Martins, T.F., Teider-Junior, P.I., Serpa, M.C.A., Barbieri, A.R.M., Bach, R.V.W., Barros-Filho, I.R., Lipinski, L.C., Dos Santos, A.P., Labruna, M.B. and Biondo, A.W. (2019) Ticks and serosurvey of anti-Rickettsia spp. antibodies in wild boars (Sus scrofa), hunting dogs and hunters of Brazil. PLoS Negl. Trop. Dis., 13(5): e0007405.

2. Brazilian Institute of Environment and Natural Renewable Resources. (2013) Instituto Brasileiro do Meio Ambiente e dos Recursos Naturais Renováveis. Instrução Normativa $\mathrm{n}^{\mathrm{o}}$ 3, 31 Jan 2013. Available from: http://www.ibama.gov. br/legislacao/javali. Retrieved on 14-10-2018.

3. Rosa, C.A., Wallau, M.O. and Pedrosa, F. (2018) Hunting as the main technique used to control wild boars in Brazil. Wildl. Soc. Bull., 42(1): 111-118.

4. Piranda, E.M., Faccini, J.L., Pinter, A., Saito, T.B., Pacheco, R.C., Hagiwara, M.K. and Labruna, M.B. (2008) Experimental infection of dogs with a Brazilian strain of Rickettsia rickettsii: Clinical and laboratory findings. Mem. Inst. Oswaldo Cruz, 103(7): 696-701.

5. Scinachi, C.A., Takeda, G.A., Mucci, L.F. and Pinter, A. (2017) Association of the occurrence of Brazilian spotted fever and Atlantic rain forest fragmentation in the São Paulo metropolitan region, Brazil. Acta Trop., 166: 225-233.

6. Allwin, B., Gokarn, N.S., Vedamanickam, S., Suhas, G.N., Vedaminckam, S., Gopal, S. and Kumar, M. (2016) The wild pig (Sus Scrofa) behavior a retrospective study. J. Dairy Vet. Anim. Res., 3(3): 115-125.

7. Barbieri, A.R., Moraes-Filho, J., Nieri-Bastos, F.A., Souza, J.C. Jr., Szabo, M.P. and Labruna, M.B. (2014) Epidemiology of Rickettsia sp. strain Atlantic rainforest in a spotted fever-endemic area of southern Brazil. Ticks Tick Borne Dis., 5(6): 848-853.

8. de Oliveira, S., Guimarães, J.N., Reckziegel, G.C., Neves, B.M.C., Araujo-Vilges, K.M., Fonseca, L.X., Pinna, F.V., Pereira, S.V.C., de Caldas, E.P., Gazeta, G.S. and Gurgel-Gonçalves, R. (2016) An update on the epidemiological situation of spotted fever in Brazil. J. Venom. Anim. Toxins Incl. Trop. Dis., 22(1): 22.

9. Polo, G., Labruna, M.B. and Ferreira, F. (2015) Satellite hyperspectral imagery to support tick-borne infectious diseases surveillance. PLoS One, 10(11): e0143736.

10. Pedrosa, F., Salerno, R., Padilha, F.V.B. and Galetti, M. (2015) Current distribution of invasive feral pigs in Brazil: Economic impacts and ecological uncertainty. Nat. Conserv., 13(1): 84-87. 